\title{
NAUJO DONORYSTĖS MODELIO REIKŠMĖ POTENCIALIŲ MIRUSIŲ DONORŲ SKAIČIUI KAUNO DONORINIAME CENTRE
}

\author{
Tomas Tamošuitis, Irena Maraulaitė, Diana Albavičiūtė, Austẻja Narakaitė, \\ Neringa Balčiūnienė \\ Lietuvos sveikatos mokslu universiteto Neurochirurgijos klinika
}

Raktažodžiai: organų donoras, donorystė dèl negrị̌tamai nutrūkusios kraujotakos, potencialus donoras, mirčių analizé, donorinis centras.

\section{Santrauka}

Organų transplantacija yra efektyviausias ir ekonomiškai naudingiausias, o kai kuriais atvejais ir vienintelis gydymo būdas esant terminaliniam vidaus organų funkcijos nepakankamumui. Pagrindinè kliūtis transplantacijai - donorinių organų trūkumas. Pasaulineje praktikoje geriausi rezultatai pasiekiami, kai kartu taikomi skirtingi donorystès modeliai: gyvoji donorytė, donorystė po smegenų mirties ir donorystė dẻl negrịžtamai nutrūkusios kraujotakos (DNNK). Nuo $2016 \mathrm{~m}$. sausio 1d., pakeitus ịstatyminę bazę, Lietuvoje atsirado galimybe ruošti DNNK, tačiau kokia galima šio modelio ịtaka organų donorų skaičiui šalyje nèra žinoma. Siekiant pamatuoto ir tvaraus DNNK programos diegimo LSMUL KK atlikta visų suaugusių pacientų mirčių, $2015 \mathrm{~m}$. registruotų Kauno klinikose ir Valstybinés teismo medicinos tarnybos (VTMT) Kauno skyriaus registre, analizé ir identifikuoti potencialūs DNNK. Analizès metu naudoti visuotinai priimti potencialaus DNNK demografiniai, ligos anamnezès ir su mirties procesu susiję laiko kriterijai. Dèl Lietuvoje galiojančių ịstatymų itraukti tik nekontroliuojami DNNK. Nustatyta, kad iš 2356 mirusiujų potencialaus DNNK kriterijus atitiko 56 mirusieji, taip padidindami potencialių organų donorų skaičių LSMUL KK donoriniame centre $119,5 \%$. Remiantis atlikta analize galima teigti, kad sékmingai ịdiegus nekontroliuojamos DNNK modeli Kauno klinikų donoriniame centre galima tikètis ženklaus donorinių organų padidẻjimo.

DNNK - donoras dèl negrịžtamai nutrūkusios kraujotakos, ŽIV - žmogaus imunodeficito virusas, CD - cukrinis diabetas, IFN - inkstų funkcijos nepakan- kamumas, CNS - centrinè nervų sistema. $\mathrm{PD}$ - potencialūs donorai, SM - smegenų mirtis, DNNK - donorai dèl negrižtamai nutrūkusios kraujotakos.

DNNK - donorai dèl negrịžtamai nutrūkusios kraujotakos, SPS - skubios pagalbos skyrius, ITS - intensyviosios terapijos skyrius.

\section{Ivadas}

Organų transplantacija pagerina gyvenimo kokybę, pailgina gyvenimo trukmę ir yra ekonomiškai naudingiausias gydymo būdas pacientams, sergantiems paskutinès stadijos inkstų nepakankamumu (1-4). Esant kepenų ar plaučių terminaliniam nepakankamumui tai gali būti vienintelis gydymo būdas (5-7). Pagrindinè kliūtis organų transplantacijai - donorinių organų trūkumas $(2,4)$. Pasaulinè sveikatos organizacija (PSO) skatina maksimaliai išnaudoti kiekvienos šalies organų donorystės galimybes siekiant užtikrinti donorinių organų poreikio patenkinimą. Tai atlikti optimizuojant vidinius resursus ir ypatingas pastangas skiriant negyvosios donorystės skatinimui, nes tokiu būdu kovojama su organų prekyba iš trečiuju šalių $(8,9)$. Lietuvoje, kaip ir kitose išsivysčiusiose Vakarų šalyse, stebimos organų donorų po smegenų mirties mažèjimo tendencijos, sąlygotos mažejančio eismo įvykių skaičiaus su letaliomis baigtimis, gerejjančių neurokritinių ligonių gydymo rezultatų (10-12). Organų trūkumo problemai spręsti ịvairios šalys naudoja skirtingas strategijas ir donorystès modelius: gyvosios donorytès skatinimą, ribinių donorų itraukimą, donorystès po smegenų mirties ir DNNK igyvendinimą. Geriausiai žinomas yra vadinamasis ispaniškasis modelis. Tai sẻkmingas visų įmanomų organų donorystės modelių apjungimas su prioritetiniu valstybės požiūriu ir specialistų bei visuomenès švietimu, leidęs pasiekti maksimalu ịmanomą rezultatą, kai pirmą kartą šalies donorų skaičius viršijo 40 vienam milijonui gyventojų(13). Kitos Europos šalys taip pat sèkmingai diegia DNNK programas ir siekia stabilaus donorinių organų skaičiaus augimo, bent 
iš dalies padengiančio didejjantị poreikị(13-15). PSO duomenimis, donorai dèl negrị̌tamai nutrūkusios kraujotakos sudaro $16,9 \%$ visų mirusių donorų(16).

DNNK organizavimas grindžiamas Mastrichto (Maastricht) klasifikacija, pagal kurią potencialūs donorai skirstomi i 4 kategorijas arba kontroliuojamus ir nekontroliuojamus donorus (17) (1 lentelè). Dèl etinių ir įstatyminių apribojimų Lietuvoje galimi tik Mastrichto 1, 2 ir 4 kategorijos nekontroliuojami DNNK donorai. Donorystès procesas tai-

1 lentelẻ. Donorų kategorijos pagal Maastricht klasifikaciją

\begin{tabular}{|c|c|c|}
\hline Kategorija & Mirties aplinkybès & Mirties laikas \\
\hline I & $\begin{array}{l}\text { Miręs atvykimo ì } \\
\text { stacionarą metu }\end{array}$ & Nekontroliuojamas \\
\hline II & $\begin{array}{l}\text { Nesėkmingas gaivinimas } \\
\text { a. Ligoninèje } \\
\text { b. Už ligoninès ribų }\end{array}$ & Nekontroliuojamas \\
\hline III & Laukiama mirtis & Kontroliuojamas \\
\hline IV & $\begin{array}{l}\text { Širdies sustojimas po } \\
\text { smegenų mirties }\end{array}$ & Nekontroliuojamas \\
\hline
\end{tabular}

2 lentelè. Potencialaus DNNK tinkamumo kriterijai

\begin{tabular}{|l|l|}
\hline $\begin{array}{l}\text { Laiko kriterijai (doku- } \\
\text { mentuota/liudininkai) }\end{array}$ & Klinikiniai kriterijai \\
\hline Amžius $\leq 60$ metų & Yra aiški mirties priežastis \\
\hline $\begin{array}{l}\leq 10 \text { min. iki gaivinimo } \\
\text { veiksmų pradžios }\end{array}$ & $\begin{array}{l}\text { Nėra sepsio ar išplitusių infekciniu } \\
\text { susirgimų, ŽIV }\end{array}$ \\
\hline $\begin{array}{l}\leq 90 \text { min. gaivinimo lai- } \\
\text { kas už ligoninės ribų }\end{array}$ & Neserga CD \\
\hline $\begin{array}{l}\text { Hospitalizacijos trukmė } \\
<3 \text { paros }\end{array}$ & Neserga Creuztfeldt - Jakobo liga \\
\hline & Neserga IFN \\
\hline & $\begin{array}{l}\text { Nèra piktybinių susirgimų, išskyrus } \\
\text { CNS auglius, bazoceliulinę odos kar- } \\
\text { cinomą }\end{array}$ \\
\hline
\end{tabular}

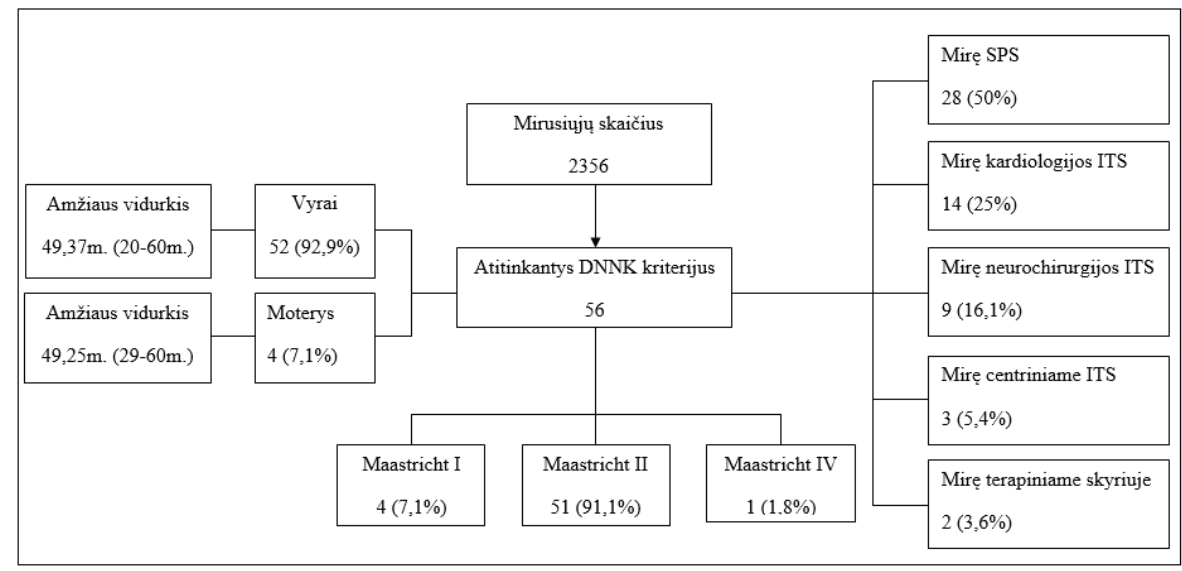

1 pav. Tiriamujų pasiskirstymas

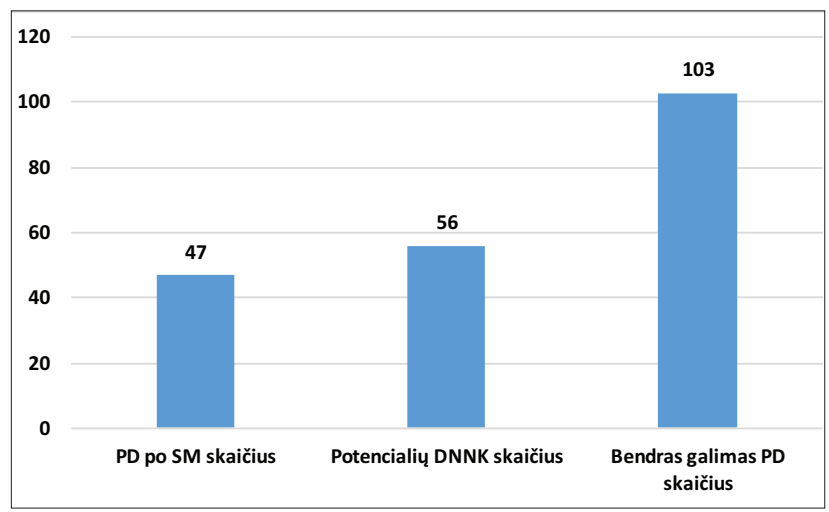

2 pav. Prognozuojamas potencialių donorų skaičiaus kitimas Lietuvos sveikatos mokslų universiteto ligoninèje Kauno klinikose 2015 metais

kant nekontroliuojamos DNNK modeli yra sudètingesnis organizaciniu požiūriu, o priklausomai nuo pasirinktos in vivo organų perfuzijos metodikos ir brangesnis nei tradiciné donorystė po smegenų mirties. Dẻl šių priežasčių didžiausias DNNK skaičius yra tose šalyse, kuriose yra galimybe ruošti Mastrichto III kategorijos arba kontroliuojamus donorus, kai kritinès būklès pacientų gydymas tampa neperspektyviu ir neatitinkančiu geriausių paciento interesų ir yra nutraukiamas gyvybę palaikantis gydymas, o po širdies darbo išsekimo inicijuojamas DNNK donorystès procesas (14, 18-20).

Vienas aktualiausių klausimų svarstant DNNK modelio tikslingumą yra donorinių organų kokybè. Inkstų transplantacijų rezultatus tyrusių studijų rezultatai patvirtina, kad donorystės tipas nepakeičia pacientų po transplantacijos baigčių (21-24). Pacientams, kuriems buvo persodinti inkstai, paimti iš DNNK donoro, buvo didesnis procentas vẻluojančios inkstų funkcijos ankstyvuoju potransplantaciniu periodu, tačiau vėlyvajame periode kreatinino kiekis ir recipientų išgyvenamumas statistiškai reikšmingai nesiskyrè, lyginant su transplantuotais organais iš donorų po smegenų mirties(13, 25). Kepenų transplantacijos rezultatai vertinami nevienareikšmiškai dèl pasitaikančių dažnesnių išeminių komplikacijų, lyginant su transplantacijomis iš donoru po smegenų mirties(26). Naudojant DNNK organus atliekamos ir plaučių transplantacijos. Nors duomenų nèra daug, bet skelbiami daug žadantys rezultatai $(27,28)$.

Svarbus DNNK aspektas yra mirusiojo artimujų sutikimas do- 
norystei, nes apsisprendimo laikas yra ypač trumpas ir vienu metu reikia suvokti žinią apie staigią artimojo mirti bei priimti sprendimą dèl organų donorystès. Vis dèlto publikuotos studijos teigia, kad potencialių donorų dèl negrịžtamai nutrūkusios kraujotakos artimieji dažniau sutinka organus atiduoti donorystei(29, 30). Manoma, kad dèl neplakančios širdies fakto jie lengviau susitaiko su artimojo mirtimi ir donorystès aktu ịprasmina artimojo netektị (29).

Lietuvoje $2016 \mathrm{~m}$. sausio 1d. pakeitus ịstatyminę bazę buvo sudarytos sąlygos donorinèms ligoninèms pradèti ruošti DNNK, tačiau šio modelio įdiegimo poveikis bendram donorinių organų skaičiui šalyje nebuvo ịvertintas anksčiau (31). Mes atlikome LSMUL Kauno klinikų donorinio centro galimybių studiją ruošiant nekontroliuojamus DNNK, vertindami 2015 m. registruotų mirčių analizę.

Tyrimo tikslas: nustatyti DNNK modelio pritaikymo įtaką bendram potencialių mirusių organų donorų skaičiui LSMUL KK.

\section{Tyrimo objektas ir metodika}

Tyrimui atlikti gautas LSMUL KK Bioetikos centro leidimas Nr. BEC-MF-422. Tyrimas atliktas retrospektyviai. Duomenys buvo renkami iš $2015 \mathrm{~m}$. LSMUL KK mirusių pacientų registro, ligos istorijų ir Valstybinès teismo medicinos tarnybos (VTMT) Kauno skyriaus ekspertizių registro. VTMT registras papildomai nagrinètas dèl tikslinès pacientų grupès, kuriems nesėkmingai taikytos reanimacinès priemonès už ligoninès ribų, kaip potencialiems nekontroliuojamiems Mastrichto II kategorijos DNNK.

Iš visų mirusiujjų atrinkti tiriamieji, kurie atitinka potencialaus donoro dèl negrižtamai nutrūkusios kraujotakos kriterijus. Tinkamumo DNNK kriterijai pateikti 2 lentelèje. Visi kriterijai pasirinkti analizuojant kitų Europos šalių patirtị atrenkant potencialius $\operatorname{DNNK}(12,32)$ bei Lietuvos nacionalinio transplantacijos biuro rengiamo dokumento pagrindu kurio kūrime dalyvauja ir šio straipsnio autoriai.

Pacientai suskirstyti ị kategorijas pagal Mastrichto klasifikaciją.

Duomenys analizuoti Excel ir SPSS 23.0.

\section{Rezultatai}

Iš viso nustatyta 2356 mirusieji, iš kurių 1500 mirę LSMUL KK ir 856 buvo atvežti į VTMT Kauno skyrių. Iš visų mirusių nustatyti 56 tiriamieji, atitinkantys DNNK kriterijus, iš kurių vyrų 52 [92,9\%], moterų 4 [7,1\%]. Vyrų amžiaus vidurkis 49,37 m. [20-60 m.], moterų 49,25 m. [29$60 \mathrm{~m}$.]. Mastrichto I kategorijai priklausè 4 (7,1 \%) tiriamieji, Mastrichto II - 51 (91,1\%), Mastrichto IV - 1 (1,8\%). Kardiologijos intensyvios terapijos skyriuje (ITS) mirusiujų atitikusių kriterijus buvo 14 (25\%), neurochirurgijos ITS -
$9(16,1 \%)$, terapijos profilio skyriuje - $2(3,6 \%)$, skubios pagalbos - 28 (50\%), centriniame ITS - 3 (5,4\%). Tiriamujų pasiskirstymas pavaizduotas 1 paveiksle.

Remiantis Nacionalinio transplantacijos biuro duomenimis, $2015 \mathrm{~m}$. LSMUL KK buvo 47 potencialūs donorai. Tais pačiais metais taikant ir DNNK modelį, bendras potencialių donorų skaičius būtų buvęs 119,5 procentų didesnis, tai yra 103 potencialūs donorai. Prognozuotas potencialių donorų skaičiaus kitimas pateiktas 2 paveiksle.

\section{Rezultatu aptarimas}

Mūsų atliktas tyrimas pirmą kartą įvertino DNNK modelio ịtaką potencialių donorų skaičiaus kitimui LSMUL KK. Kadangi LSMUL KK donorinis centras paruošia beveik 50\% visų šalies donorų, tai ženklus potencialių donorų skaičiaus didejjimas turètų įtakos ir visos šalies donorystès rezultatams(33). Mūsų tyrimo metu nustatytas vidutinis potencialių donorų amžius yra mažiau nei 50 metų. Bendrame senstančios Vakarų visuomenès fone, taip pat ir vis vyresnių potencialių donorų po smegenų mirties kontekste toks amžius yra santykinai jaunas ir galimai donorystei aukojami organai gyvybingesni nei ribinių donorų organai po smegenų mirties(34).

Literatūros duomenimis, iš visų kategorijų potencialių DNNK efektyviais tampa 40-80proc. donorų(35). Iš nekontroliuojamų DNNK efektyviais tampa 47-64 proc. donorų $(15,36)$. Dažniausios kliūtys potencialiems donorams tapti efektyviais šiame modelyje yra: artimujų prieštaravimas donorystei, techninès ir organizacinès problemos, apmokytų specialistų trūkumas, nepakankama eksplantuotų organų kokybė dèl per ilgo šiltos išemijos laiko. Didžiulis nekontroliuojamų DNNK potencialas praplečiant potencialių donorų ratą literatūroje minimas vertinant šalių su gerai išvystytu donorinių centrų tinklu perspektyvas(37), tačiau tik keletas šaliu įgyvendino sėkmingas nekontroliuojamų DNNK programas dẻl ženklių organizacinių, techninių, etinių ir moralinių iššūkių $(38,39)$. Labiausiai pažengusios šalys, kurioms pavyko sèkmingai pradèti ir sistemingai vystyti nekontroliuojamų DNNK programas, yra Ispanija, Prancūzija ir Nyderlandai. Net $90 \%$ efektyvių donorų šiose šalyse tapo Mastrichto II kategorijos mirusieji, t.y. nesėkmingai gaivinti už ligoninès ribų (40). Tokie potencialūs DNNK pristatomi ị ligonines greitosios pagalbos medikų su aiškia organų donorystės intensija ir, esant galimybei, jau aptarus situaciją su artimaisiais. Mūsų analizejje nustatyti 28 šios kategorijos atvejai arba 50\% iš visu atitikusių pirminius DNNK kriterijus potencialių donorų. Visos šalys turejjo aiškiai dokumentuotus veiksmus mirties po nesèkmingo gaivinimo atvejų, gerą komunikaciją tarp greitosios pagalbos medikų, skubios medicinos specialistų ir donorų koordinatorių, bei 
aiškias organų prezervacijos metodikas ir etinių klausimų sprendimus $(32,41,42)$. Šiuo metu Lietuvoje tokio modelio pritaikymui, mūsų žiniomis, nèra pasiruošta nei viename donoriniame centre.

Kita didelè mūsų analizejje nustatytų potencialių nekontroliuojamų DNNK grupe yra intensyviosios terapijos skyriuose (ITS) nesėkmingai gaivinti pacientai. Didžioji jų dalis gydyta kardiologinio profilio ITS. Tai visiškai priešingi rezultatai lyginant su potencialiais donorais po smegenu mirties, nes absoliuti dauguma šių pacientų identifikuojami neurologinio profilio ITS. Taigi atsiranda galimybe i naują donorystès programą ịtraukti didelę grupę kritinès būklès kardiologinių pacientų, kurie miršta be galimybès paaukoti savo organus donorystès tikslais. Mūsų analizèje šios kategorijos potencialūs DNNK sudare 26 iš 56 atvejų ir turètų būti pirminè tikslinè grupè pradedant programą analizuojamame donoriniame centre.

Mūsų atliktame tyrime identifikuotas vienintelis Mastrichto IV kategorijos potencialus DNNK yra tik santykinai nekontroliuojamas, kadangi jau esant diagnozuotai smegenų mirčiai tiek artimieji, tiek medicinos personalas jau galètụ numanyti šio paciento baigtị ir rengtis donorystès procesui iš anksto.

\section{Išvados}

LSMUL KK donorinis centras įdiegdamas DNNK modeli turi galimybes ženkliai padidinti potencialių mirusių organų donorų skaičių, o efektyvių donorų skaičiaus didèjimas taptų proporcingas investicijoms ị techninę bazę, specialistų komandų ruošimą ir visuomenès supratingumo bei palaikymo ugdymą.

\section{Literatūra}

1. Manara AR, Murphy PG, O'Callaghan G. Donation after circulatory death. British Journal of Anaesthesia 2012; 108 Suppl 1:1108-21.

2. Manyalich M, Guasch X, Gomez MP, Páez G, Teixeira L, Consortium O. Organ donation European Quality System: ODEQUS project methodology. Transplant Proc 2013; 45(10):3462-5.

https://doi.org/10.1016/j.transproceed.2013.09.009

3. Grinyó JM. Why is organ transplantation clinically important? Cold Spring Harb Perspect Med 2013;3(6).

4. Saidi RF, Hejazii Kenari SK. Challenges of organ shortage for transplantation: solutions and opportunities. Int J Organ Transplant Med 2014; 5(3):87-96.

5. Pascher A, Nebrig M, Neuhaus P. Irreversible liver failure: treatment by transplantation: part 3 of a series on liver cirrhosis. Deutsches Ärzteblatt International 2013; 110(10):167-73.

6. Farkas S, Hackl C, Schlitt HJ. Overview of the indications and contraindications for liver transplantation. Cold Spring Harbor
Perspectives in Medicine 2014; 4(5).

7. Hartert M, Senbaklavaci Ö, Gohrbandt B, Fischer BM, Buhl $\mathrm{R}$, Vahl CF. Lung transplantation: a treatment option in end-stage lung disease. Deutsches Ärzteblatt International 2014;111(7):107-16.

8. The declaration of Istanbul on organ trafficking and transplant tourism. Indian Journal of Nephrology 2008;18(3):135-40.

9. Delmonico FL, Dominguez-Gil B, Matesanz R, Noel L. A call for government accountability to achieve national self-sufficiency in organ donation and transplantation. Lancet (London, England) 2011;378(9800):1414-8.

https://doi.org/10.1016/S0140-6736(11)61486-4

10. LR Oficialiosios statistikos portalas: Lietuvos statistikos departamentas. Available from: https://osp.stat.gov.lt.

11. Saidi RF, Bradley J, Greer D, Luskin R, O'Connor K, Delmonico F. et al. Changing pattern of organ donation at a single center: are potential brain dead donors being lost to donation after cardiac death? American Journal of Transplantation: Official Journal of the American Society of Transplantation and the American Society of Transplant Surgeons 2010;10(11):253640.

https://doi.org/10.1111/j.1600-6143.2010.03215.x

12. British Transplant Society guidelines 2004 . Available from: https://bts.org.uk/wp-content/uploads/2016/09/NonHeart.pdf.

13. Matesanz R, Dominguez-Gil B, Coll E, Mahillo B, Marazuela R. How Spain Reached 40 Deceased Organ Donors per Million Population. American journal of transplantation : official journal of the American Society of Transplantation and the American Society of Transplant Surgeons 2017;17(6):1447-54. https://doi.org/10.1111/ajt.14104

14. Leiden H, Haase-Kromwijk B, Hoitsma A, Jansen N. Controlled donation after circulatory death in the Netherlands: more organs, more efforts. Neth J Med 2016;74(7):285-91.

15. Le Dinh H, Monard J, Delbouille MH, Hans MF, Weekers L, Bonvoisin C. et al. A more than $20 \%$ increase in deceased-donor organ procurement and transplantation activity after the use of donation after circulatory death. Transplant Proc 2014; 46(1): 9-13.

https://doi.org/10.1016/j.transproceed.2013.10.012

16. Global Observatory on Donation and Transplantation 2015. Available from: http://www.transplant-observatory.org/ countded/.

17. Kootstra G, Daemen JH, Oomen AP. Categories of non-heartbeating donors. Transplant Proc 1995;27(5):2893-4.

18. Desschans B, Evrard P, Society CTSotBT. Organ donation and transplantation statistics in Belgium for 2012 and 2013. Transplant Proc 2014;46(9):3124-6.

https://doi.org/10.1016/j.transproceed.2014.09.170

19. Johnson RJ, Bradbury LL, Martin K, Neuberger J, Registry UT. Organ donation and transplantation in the UK-the last decade: a report from the UK national transplant registry. Transplantation 2014;97 Suppl 1:S1-S27. 
20. Hessheimer AJ, Domínguez-Gil B, Fondevila C, Matesanz R. Controlled donation after circulatory determination of death in spain. Am J Transplant 2016;16(7):2239-40.

https://doi.org/10.1111/ajt.13762

21. Summers DM, Watson CJ, Pettigrew GJ, Johnson RJ, Collett D, Neuberger JM. et al. Kidney donation after circulatory death (DCD): state of the art. Kidney Int 2015;88(2):241-9. https://doi.org/10.1038/ki.2015.88

22. Singh RP, Farney AC, Rogers J, Zuckerman J, Reeves-Daniel A, Hartmann E, et al. Kidney transplantation from donation after cardiac death donors: lack of impact of delayed graft function on post-transplant outcomes. Clin Transplant 2011;25(2): 255-64. https://doi.org/10.1111/j.1399-0012.2010.01241.x

23. Shahrestani S, Webster AC, Lam VW, Yuen L, Ryan B, Pleass HC. et al. Outcomes from pancreatic transplantation in donation after cardiac death: a systematic review and meta-analysis. Transplantation 2017;101(1):122-30. https://doi.org/10.1097/TP.0000000000001084

24. Nagaraja P, Roberts GW, Stephens M, Horvath S, Kaposztas $Z$, Chavez R. et al. Impact of expanded criteria variables on outcomes of kidney transplantation from donors after cardiac death. Transplantation 2015;99(1):226-31. https://doi.org/10.1097/TP.0000000000000304

25. Miranda-Utrera N, Medina-Polo J, Pamplona-Casamayor M, Passas-Martínez JB, Rodríguez-Antolín A, de la Rosa Kehrmann F. et al. Uncontrolled non heart beating donors (types i-ii) with normothermic recirculation vs. heart beating donors: evaluation of functional results and survival. Actas Urol Esp 2015;39(7):429-34

https://doi.org/10.1016/j.acuro.2015.01.005

26. Fondevila C, Hessheimer AJ, Ruiz A, Calatayud D, Ferrer J, Charco R. et al. Liver transplant using donors after unexpected cardiac death: novel preservation protocol and acceptance criteria. American journal of transplantation: official journal of the American Society of Transplantation and the American Society of Transplant Surgeons 2007;7(7):1849-55. https://doi.org/10.1111/j.1600-6143.2007.01846.x

27. Gomez-de-Antonio D, Campo-Canaveral JL, Crowley S, Valdivia D, Cordoba M, Moradiellos J. et al. Clinical lung transplantation from uncontrolled non-heart-beating donors revisited. The Journal of Heart and Lung Transplantation: the Official Publication of the International Society for Heart Transplantation 2012;31(4):349-53.

https://doi.org/10.1016/j.healun.2011.12.007

28. de Antonio DG, Marcos R, Laporta R, Mora G, Garcia-Gallo $\mathrm{C}$, Gamez P. et al. Results of clinical lung transplant from uncontrolled non-heart-beating donors. The Journal of heart and lung transplantation: the official publication of the international society for heart transplantation 2007;26(5):529-34.

https://doi.org/10.1016/j.healun.2007.01.028

29. Andrés A, Morales E, Vázquez S, Cebrian MP, Nu-o E, Ortu- o T. et al. Lower rate of family refusal for organ donation in non heart beating versus brain dead donors. Transplant Proc 2009;41(6):2304-5.

https://doi.org/10.1016/j.transproceed.2009.06.039

30. Martin-Villen L, Revuelto-Rey J, Aldabo-Pallas T, CorreaChamorro E, Gallego-Corpa A, Ruiz Del Portal-Ruiz Granados P. et al. Non heart beating donor program: results after 3 years of experience. Transplant Proc 2015;47(9):2567-9. https://doi.org/10.1016/j.transproceed.2015.09.050

31. Lietuvos Respublikos žmogaus mirties nustatymo ir kritinių būklių įstatymas, 2017.

32. Donation after circulatory death: current situation and recommendations. Spanish National Consensus Document 2012. Available from: http://www.ont.es/infesp/Paginas/DocumentosdeConsenso.aspx.

33. Lietuvos Nacionalinis Transplantacijos Biuras prie LR SAM. Available from: http://www.transplantacija.lt/content/charts/ donoryste/rodikliailietuvoje.lt.html.

34. Hubbard WJ, Dashti N. Ageing and transplantation - a topic for biomedicine or bioethics? Ageing and Disease 2011;2(2):181-5.

35. Akoh JA. Kidney donation after cardiac death. World J Nephrol 2012;1(3):79-91. https://doi.org/10.5527/wjn.v1.i3.79

36. Mi-ambres E, Suberviola B, Guerra C, Lavid N, Lassalle M, González-Castro A. et al. Experience of a Maastricht type II non heart beating donor program in a small city: preliminary results. Med Intensiva 2015;39(7):433-41.

37. Roberts KJ, Bramhall S, Mayer D, Muiesan P. Uncontrolled organ donation following prehospital cardiac arrest: a potential solution to the shortage of organ donors in the United Kingdom? Transplant international: Official Journal of the European Society for Organ Transplantation 2011;24(5):477-81.

38. Dominguez-Gil B, Haase-Kromwijk B, Van Leiden H, Neuberger J, Coene L, Morel P. et al. Current situation of donation after circulatory death in European countries. Transplant international: Official Journal of the European Society for Organ Transplantation 2011;24(7):676-86. https://doi.org/10.1111/j.1432-2277.2011.01257.x

39. Wall SP, Kaufman BJ, Gilbert AJ, Yushkov Y, Goldstein M, Rivera JE. et al. Derivation of the uncontrolled donation after circulatory determination of death protocol for New York city. American Journal of Transplantation: Official Journal of the American Ssciety of transplantation and the American Society of Transplant Surgeons 2011;11(7):1417-26. https://doi.org/10.1111/j.1600-6143.2011.03582.x

40. Dominguez-Gil B, Duranteau J, Mateos A, Nunez JR, Cheisson $\mathrm{G}$, Corral E. et al. Uncontrolled donation after circulatory death: European practices and recommendations for the development and optimization of an effective programme. Transplant international: Official Journal of the European Society for Organ Transplantation 2016;29(8):842-59.

https://doi.org/10.1111/tri.12734

41. Dutch national protocol. Model protocol organ-and tissue 
donation 2012.

Available from: https://www.transplantatiestichting.nl/

42. Conditions à respecter pour réaliser des prélèvements de reins sur des donneurs décédés aprés arrêt cardiaque dans un établissement de santé autorisé aux prélèvements d'organes 2015. Available from: https:/www.agence-biomedecine.fr/

\section{IMPACT OF NEW ORGAN DONATION MODEL TO THE POTENTIAL DECEASED DONOR POOL IN THE KAUNAS DONOR CENTER}

T. Tamošuitis, I. Maraulaitė, D. Albavičiūtė, A. Narakaitė,

\section{N. Balčiūnienė}

Key words: death analysis, DCD, donor center, organ donor, potential donor.

Summary

Organ transplantation is recognized as a most clinically and economically effective treatment for terminal and irreversible solid organ failure and remaining the only way of treatment in certain circumstances. Main limitation of successful transplant program worldwide is shortage of donor organs. Best possible organ donation results achievable when implementing all models of organ donation together: live donation and deceased donation after brain (DBD) or circulatory death (DCD). DCD is available in Lithuania since 2016 due to the changes in legislation but there was no analysis of possible impact on potential donor numbers after implementing of new program. We analysed all registered deaths in The Hospital of Lithuanian University of Health Sciences (LSMU) Kaunas clinics and Kaunas regional Coroner office in 2015 and identified potential uncontrolled DCD's according to Maastricht classification. Widely accepted demographic, illness profile and death timing criteria were used identifying potential DCD. There were 56 individuals fulfilling potential DCD criteria out of total 2356 registered deaths increasing total deceased potential donor pool by $119.5 \%$ in a single donor center. We conclude that implementation of new deceased organ donation model would have a significant positive impact in total potential deceased donor numbers in Kaunas donor center.

Correspondence to: tomas.tamosuitis@kaunoklinikos.lt

Gauta 2017-10-25 